\title{
Research in Continuing Education Programme
}

\author{
C. Meribha Christy ${ }^{1}$, V. Hemavathy ${ }^{2}$ \\ (Associate professor) Sree Balaji College of Nursing, Chennai \\ ${ }^{2}$ Principal and Professor, Sree Balaji College of Nursing, Chennai, India
}

\begin{abstract}
Research is systematic enquiry that uses disciplined methods to answer questions or solve problems. The ultimate goal of research is to develop, refine, and expand a body of knowledge. The main advantages of continuing nursing education are acquired specialized skill of personnel and meet technological adjuncts, clinical specialist is needed for direct patient care and for teaching and consultative roles to help the student and staff nurses to reach higher level of competency and it provides opportunities for educational growth compatible with the realities of both work situation and the home responsibilities. In the world, scientific advancement, technologic innovation, social changes are occurring rapidly and new patterns of health care personnel are emerging to these needs and demands qualified nurses are essential.
\end{abstract}

Keywords: Research, continuing education, nursing research

\section{Introduction}

Human are curious in nature. Human curiosity has lead to many discoveries that aid us in our daily lives. Simple hand washing procedure, currently used by nurses, greatly reduces the spread of infection. Length of time required to determine body temperature accurately helps to monitor client's progress more effectively. Whatever person discover by the means of logic principle we call it as Research.

\section{Research}

\section{Definition of Research}

Research is systematic enquiry that uses disciplined methods to answer questions or solve problems. The ultimate goal of research is to develop, refine, and expand a body of knowledge.

\section{Definition of Nursing Research}

Nursing research is systematic enquiry designed to develop trustworthy evidence about issues of important to the nursing profession include nursing practice, education, administration and informatics.

\section{Purpose of Nursing Research}

- Nursing research seeks answers to questions in an orderly systematic way.

- Nursing research helps to prove more effective nursing care.

- Nursing research helps to document the unique role, nursing plays in the health care system.

- Nursing research extends the way of information not only the few nurses asking the question, but also for other nurses seeks answers for the same problems.

- Nursing research helps to determine the parameters of nursing.

- It focuses on the effectiveness of nursing intervention and activities for various groups of client.

- Some nursing research findings help to eliminate nursing action that has no effect on the achievement of desired client out come.

- Nursing research helps to assess the cost effectiveness in the health care status of patient.
- Nursing research describes characteristics or quality of the particular nursing situation about which little is known.

- Nursing research predicts the possible outcome of certain nursing decision made in related to patient care.

- Nursing research controls the occurrence of undesired client out comes.

- Nursing research initiate to achieve desired client behavior.

\section{The Two Categories of People In Nursing Research.}

\section{Consumer}

Who read report of studies typically to keep up to date on information that might be relevant to their practice or to develop new skill.

\section{Producer;}

Nurses who actively participate in the design and implementation of scientific studies.

\section{Continuing Education}

\section{Introduction}

Continuing education program should be developed by nurses and conducted with in nursing or in general education system cooperation with the nursing

\section{Definition to Continuing Education}

„,Continuing education is all the learning activities that occurs after an individual has completed his basic education ${ }^{\text {eee }}$-Cooper

„,That education which builds on previous education ${ }^{\text {ece }}$ Shannon.

\section{Need for Continuing Education}

- To ensure safe and effective nursing care. Nurses need to keep abreast with interest knowledge and technical advances.

- To meet the need of population.

- Development of nurses will occur by updating their knowledge and prepare them for specialization.

- For carrier advancement 


\section{International Journal of Science and Research (IJSR) \\ ISSN (Online): 2319-7064}

Index Copernicus Value (2013): 6.14 | Impact Factor (2014): 5.611

- Professional role are altered as socially changes and as new knowledge and technology emerges.

- If the nursing professional is to respond effectively, to the challenge of developing wise leadership and competent practitioner, current social changes must be recognized and future one foreseen.

- To acquired specialized skill of personnel and meet technological adjuncts.

- Clinical specialist is needed for direct patient care and for teaching and consultative roles to help the student and staff nurses to reach higher level of competency

- Professional role are altered as socially changes and as new knowledge and technology emerges.

- If the nursing professional is to respond effectively, to the challenge of developing wise leadership and competent practitioner, current social changes must be recognized and future one foreseen.

- To acquired specialized skill of personnel and meet technological adjuncts.

- Clinical specialist is needed for direct patient care and for teaching and consultative roles to help the student and staff nurses to reach higher level of competency.

- It provides opportunities for educational growth compatible with the realities of both work situation and the home responsibilities.

- In the world, scientific advancement, technologic innovation, social changes are occurring rapidly and new patterns of health care personnel are emerging to these needs and demands qualified nurses are essential.

- To maintain their roles as beside nurses and to assume more supervisor, administrative and dedicated medical function to specialize and to generalize their practice continuing nursing education is essential

Functions of Continuing Education

- To meet the health needs \& public expectations.

- To develop the practicing ability of the nurses.

- Recruitment function.

- Recognize gaps in their knowledge.

- To test ability to do final academic study.

- To improve the communication between the participants, faculty, community $\&$ health sectors.

- To test the participants ability to do formal academic study.

- To shape \& support university educational policies \& practice.

- To ensure the quality of education.

- To grand budget for extension studies.

- To maintain academic standards

- To meet educational requirements.

\section{Research in Continuing Education}

Importance of Research in Continuing Education

- To attain Magnet status.

- To know the effectiveness of teaching method followed in CEP.

- $\quad$ To identify \& increase number of participants involved in CEP.

- To uncover the existing problem \& to take remedial measures.
- To investigate the possible causes of a problem.

- It is an evaluating tool for a CEP.

\section{Research Strategies Used}

- The research approach in the area of continuing education may be as follows.

- Quasi experimental design.

- Observational method.

- Survey method.

- Expose facto design.

- Correlation research design.

\section{Areas of Implication of Research In CEP.}

- Student.

- Faculty.

- Teaching method.

- Evaluation of study over curriculum of various nursing training programme.

Various Research Study Conducted On Continuing Education.

1. Research on conference \& workshop and number of participants to this programme.

2. Research on effect of web based education.

3. Research on need of CEP for nurses.

4. Effectiveness of CEP IN Bio statistic \& Research methodology in nursing.

\section{Research On Conference And Workshop}

\section{Methods}

Design; A qualitative research design was used to investigate how beside nurses utilize attendance at conference $\&$ workshop as continuing educational tools.

\section{Sample plan;}

1. RNs (full time work at bedside)

2. Nurses (full time work at bedside)

\section{Data collection \& Analysis}

The area of research conducted is teaching hospitals. A research question containing 35 detailed questions. That questionnaire contains whether any relationship exist between age, marital status, parental status, \& RNs participation in CEP in relation to year of experiences. The response rate was $74 \%$ (137 out of 189 participants) participants were asked to fill the questionnaire within 15 minutes.

\section{Discussion}

This research demonstrates significant interest by hospital bedside RNs, who wish to continue their education by attending conferences \& workshop. But shift work is a necessary inconvenience for bedside $\mathrm{RNs}$ in terms of continuing education. Because of the care that patients requires on a 24 hours.

\section{Research on Web Based CEP}

Web based education was introduced in continuing education. It can overcome some traditional barriers like difficulty in accessing program, lake of time during 


\section{International Journal of Science and Research (IJSR) \\ ISSN (Online): 2319-7064}

Index Copernicus Value (2013): 6.14 | Impact Factor (2014): 5.611

scheduled shift, insufficient work load relief. Web based \& computer education is a feasible option for educating professionals compared with printed/lecture based CEP.

Main Goal; Is to incorporate audio, video, graphics, tax \& interact in to the learning process.

\section{Objectives}

To define research based practice

To identify different role that used in REB.

To define 3 process in REB.

To discusses how REB can be implemented.

\section{Function}

- To develop a structured format.

- To ensure a standardized program.

- To incorporate ANA \& Magnet status standards. To identify outcome criteria.

- To include all RNs.

- To establish time frame for completion of the program.

- To co-ordinate for implementation.

- To maintain records, keeping for evaluation

\section{Advantages}

- It allows learners to face themselves $\&$ individualize the program.

- The user can access the faculty's explanation as many times as needed.

- The system allows users to rewind, hear,

- \& see information additional times, if needed.

- Being able to enter \& leave the program as time and energy permit is a key advantage of online education.

- Multiple users can access the program at the same time from work a home via the internet.

- Can hear the lecture while viewing the slides.

\section{Result}

64 RNs viewed both the audio \& visual portion of the education programs through \& completed a written evaluation.

All the staff nurses agreed that the learning objectives were achieved \& they were satisfied with the program \& their personal learning need were met. Typical comments includes ,Excellent means of obtaining continuing education $^{\text {eee }}$

\section{Research on Need of CEP for Nurses}

This research was concerned with the perceived needs of certain groups of trained nurses for educational opportunities to upgrade nursing education. The focus of the study was up on those charges - Nurse Grade. However 2 samples was designed to collect data

\section{Sample;}

General Nurses

Midwifes (specialty) who were registered.

Much of the initial work of the research was concerned with a need to identify, components of nursing so that they could be an understanding of what before examines what is required to maintain competency by updating knowledge.

\section{Sample Design}

The cluster sample design were used to this study.248 Nurses for 6 hospital authorities in one region with appropriate proportion from each districts, grade \& specialty were obtained.

\section{Tools \& Data Collection}

A survey approach was undertaken, a questionnaire being the main tool used, scale one related to satisfaction with reading facilities, and scale two related to satisfaction with the availability of educational program. It consists of 23 questions, some are open end, and some are dichotomous. In order to get reliability \& validity test \& retest was conducted.5 point scale were used, it contains ,very dissatisfaction to very satisfaction ${ }^{\text {ee }}$

\section{Result}

\section{Satisfaction with Program}

Grade Nurses; only $17 \%$ of nursing officers scored in the dissatisfaction level of the level where as the charge nurses the $\%$ was $49 \%$. Specialty also had an influence because the proportion of general charge nurses who scored as dissatisfied was $54 \%$ \& of midwifery charge nurses $19 \%$. Marital status; $59 \%$ of married responders but $37 \%$ of those were not married

Night duty; $59 \%$ were recorded dissatisfaction

\section{Satisfaction With Reading Facilities}

Research evident that post basic educational program were more likely to use libraries than others. Among those who scored in the "satisfied ${ }^{\text {ee }}$ region of this scale $70 \%$ were participant in post basic educational courses.

And Nurses are not enthusiastic to read from libraries EFFECTIVENESS OF CEP IN BIOSTATISTICS AND RESEARCH METHODOLOGY

This CEP was conducted to know the knowledge of nursing students and their teachers on biostatistics and research methodology

\section{Sample}

M. Sc (N) students

B. Sc (N) students

And their teachers.

\section{Aim Of This Study}

Assess the knowledge among P G students \& their teachers about research methodology \& biostatistics.

To evaluate the effectiveness of CEP on Research methodology and bio statistics

\section{Sample Plan}

Person who never had training in that two part were included others were excluded.

\section{Study Design}

Quasi excremental study design were used

\author{
Intervention Used \\ Group discussion \\ Practical Group work
}




\section{Topic Covered}

Literature review

Research design

Conceptual and theoretical frame work

Problem statement

Operation definition

Tool construction

Organization of data

Description statistics

Testing hypothesis

\section{Data Collection}

Pre \& post test questionnaire were completed by 70 participant, were given time for complete the question is 15 minutes.

Questionnaire consist of 6 question related to socio demographic data \& 10MCQ. Each in the field of research and statistics. It was administered to participant before starting $\&$ at the end of the CEP.

\section{Result}

Increases the mean score related to knowledge of biostatistics and research methodology.

\section{Theory Application}

System model is applied in this topic

Various need for CEP and present problem which will interfere with CEP can be of input. Conducting research to and introducing new method of CEP is through put. The increased number of participant can be of output.

\section{Conclusion}

In this 21st century nurses deserve a system that art, professional practices. A momentum in escalating EBP \& Nurses practicing in 21 st century must embrace it principles as an approach in critical care and professional accountability.

\section{References}

[1] C.M. Prasad. "Principles \& Practice of Management" $6^{\text {th }}$ edition, 2004, Sultan Chand \& Sons Publication - Page No. $214-18$.

[2] Chabra, 2003 "Nursing research", $8^{\text {th }}$ Edition; Darpar Rai and Co., New Delhi.

[3] Francis, C.M. Soyza,M. C. de, (2000) "Hospital Administration" $3^{\text {rd }}$ edition, Jaypee Brothers, New Delhi $-270-281$.

[4] Heinz Weitrich and Harold Knootz, "A text book of research" $10^{\text {th }}$ edition. Mc Graw Hill Publication - Page No. $519-602$.

[5] Jawahar Lal, "research \&Management", $5^{\text {th }}$ edition, Mc Graw, Hill publication page - 519-602.

[6] Jha. S.M. 2005 "Hospital Management" Ist edition: Himalaya Publishing House, Mumbai. Pg. 344 - 368. 